\title{
PENERAPAN REALISTIC MATHEMATICS EDUCATION BERBASIS BUDAYA ACEH TERHADAP PENINGKATAN HASIL BELAJAR DAN AKTIVITAS SISWA
}

\author{
Nur Azmi \\ ${ }^{1}$ Institut Agama Islam Negeri Lhokseumawe, Jl. Banda Aceh-Medan, Buket Rata Kota Lhokseumawe. 24352, Indonesia \\ Email: nurazmi_math@yahoo.co.id
}

\begin{abstract}
Abstrak
Penelitian ini bertujuan untuk mengkaji penerapan pendekatan RME berbasis budaya Aceh terhadap peningkatan hasil belajar matematika dan aktivitas siswa. Penelitian ini dikategorikan sebagai penelitian kuantitatif dengan menggunakan deskriptif dan statistik inferensial. Desain penelitian ini berbentuk pre-test post-test control group design, dengan populasi seluruh siswa kelas II SD Negeri 2 Kota Lhokseumawe, dengan mengambil sampel dua kelas (kelas eksprimen dan kelas kontrol) melalui teknik random sampling. Pengumpulan data dilakukan dengan dua jenis instrumen yaitu tes dan non tes. Tes meliputi soal untuk mengukur hasil belajar matematika siswa, dan non-tes berupa data observer terhadap aktivitas siswa pada pembelajaran matematika realistik berbasis budaya Aceh. Uji statistik yang digunakan dalam penelitian ini adalah statistik deskriptif dan inferensial. Berdasarkan hasil penelitian, diperoleh bahwa 1) Peningkatan hasil belajar matematika siswa yang memperoleh pedekatan pembelajaran matematika realistik berbasis budaya Aceh lebih tinggi daripada peningkatan hasil belajar matematika siswa yang memperoleh pembelajaran biasa / konvensional. (2)Tidak terdapat interaksi antara pendekatan pembelajaran dengan kemampuan awal yang dimiliki siswa (3) Aktivitas siswa dengan pembelajaran matematika realistik berbasis budaya Aceh lebih aktif dan meningkat serta siswa memberi respon positif.
\end{abstract}

Kata kunci :RME Berbasis Budaya Aceh, Hasil Belajar, Aktivitas siswa

\begin{abstract}
This study aims to examine the application of the Aceh culture-based RME approach to improving mathematics learning outcomes and student activities. This research is categorized as quantitative research using descriptive and inferential statistics. The design of this study was in the form of pre-test post-test control group design, with a population of all grade II students of SD Negeri 2 Lhokseumawe City, by taking a sample of two classes (experimental and control classes) through random sampling techniques. Data collection was carried out with two types of instruments, namely test and non-test. The test includes questions to measure student mathematics learning outcomes, and non-tests in the form of observer data on student activities in realistic culture-based mathematics learning in Aceh. The statistical tests used in this study are descriptive and inferential statistics. Based on the results of the study, it was found that 1) The increase in mathematics learning outcomes of students who gained a realistic approach to learning mathematics based on Acehnese culture was higher than the increase in mathematics learning outcomes of students who obtained conventional / conventional learning. (2) There is no interaction between the learning approach and the students' initial abilities (3) Student activities with realistic learning of Acehnese culture-based mathematics are more active and increased and students respond positively.
\end{abstract}

Keywords: Aceh Culture-Based RME, Students’ Achievement, Student activities.

\section{PENDAHULUAN}

Budaya merupakan kultur serta perilaku dan langgam yang tumbuh dan berkembang dalam satu komunitas dalam setiap lapisan masyarakat, yang bentuk kohesi sosial dan tentu sesuatu yang tidak bisa dipisahkan dalam kehidupan sehari-hari masyarakat Aceh. Budaya Aceh merupakan budaya akulturasi, dimana adalah penggabungan beberapa budaya, dari berbagai eksponen kehidupan, bisa disebut perpaduan budaya hindu yang disempurnakan dengan budaya islam pasca Islam dibawa pedagang dari jazirah arab ke sumatera, yang hal tersebut mengewanjantahkan serta penisbahan wajib kepada dunia pendidikan. 
Dalam pengembangan pendidikan masyarakat Aceh dewasa tempo dulu pendidikan dan budaya tidak bisa dikotomikan secara terpisah, saling melengkapi untuk membangun karakter personal masyarakat Aceh secara objektif. Seperti budaya konsep " $d o$ da idi" (alunan yang didengungkan oleh ibu - ibu saat menidurkan sang bayi sejak ayunan, yang salah satu bait syairnya adalah " Rayeuk Sinyak Tajak Beut dan Sikula, beuteubleut mata peunerang poma, meuguna keuagama ngon keubangsa " merupakan pesan moral yang baik secara pendidikan maupun dalam hal agama yang ditanamkan pada anak usia dini yang sudah menjadi budaya turun temurun dari nenek moyang orang aceh sejak dahulu.

Namun selama ini seiring perkembangan zaman pelestarian budaya kian terabaikan, baik dalam kegiatan sosial maupun pendidikan. Banyak sekolah mulai tingkat anak usia dini sampai sekolah menengah di Aceh berlomba mempersembahkan pelayanan yang terbaik, dan lulusan berprestasi, seperti menawarkan dua bahasa (bilingual), sekolah berbasis pesantren (pesantren terpadu), sekolah bertaraf international dan sebagainya, namun hanya sedikit bahkan hampir tidak ada sekolah yang menerapkan pengembangan budaya Aceh dalam pembelajaran maupun kurikulumnya.

Matematika merupakan disiplin ilmu yang penting untuk dikuasai namun dianggap pelajaran yang sulit serta rumit untuk dipahami. Berdasarkan Observasi awal, SD Negeri 2 Lhokseumawe siswa masih mengalami kesulitan memahami matematika terlihat juga siswa tidak lagi menggunakan bahasa Aceh dalam berkomunikasi disekolah, baik itu sesama teman maupun dengan guru. Disamping itu dari hasil wawancara dengan bebapa siswa, ada banyak hal tentang budaya Aceh yang siswa tidak tahu, hal ini menjadi awal mulanya nilai - nilai budaya itu sendiri akan tersingkirkan dan terlupakan bagi generasi mendatang. Beranjak dari kebutuhan inilah pentingnya pengenalan budaya pada siswa - siswa di Aceh dalam pembelajaran dikelas sejak siswa duduk disekolah dasar. Salah satu langkah yang bisa ditempuh dalam pembelajaran matematika yaitu mengajarkan matematika menjadi lebih bermakna dengan mengangkat masalah nyata berbasis budaya Aceh dalam pembelajaran matematika.

Salah satu model pembelajaran matematika yang memulai pembelajaran dengan masalah nyata dalam kehidupan yaitu reaistik matematic education (RME). Di Indonesia sendiri Realistic Mathematic Education (RME) dikenal dengan istilah PMRI (Pendidikan Matematika Realistik Indonesia) atau sering disebut dengan PMR. Pendekatan pembelajaran matematika realistik (PMR) didasarkan pada pandangan Freudenthal (dalam Suryadi: 2012:46) terhadap pendidikan matematika yaitu: (1) matematika merupakan aktivitas manusia, dan (2) matematika harus dipelajari secara bermakna.

Di Provinsi Nanggroe Aceh Darussalam pendidikan matematika realistik (PMR) mulai disosialisasikan sejak tahun 2006 pasca bencana Tsunami melanda daerah tersebut. Mulanya PMR dicobakan pada sekolah dasar (SD) disekitar Banda Aceh dan Aceh Besar sebanyak 36 sekolah melalui binaan guru-guru matematika sekolah dasar oleh Universitas Syiah Kuala (Sembiring. R:2010). Selanjutnya PMR semakin meluas dikalangan pendidikan khususnya matematika di Aceh melalui sosialisasi dinas pendidikan, workshop guru matematika, penelitian tingkat dosen maupun mahasiswa, mulai adanya buku teks yang menuliskan kelebihan pendekatan PMR dan pelatihanpelatihan guru matematika tentang pembelajaran yang bermakna.

Kegiatan pembelajaran PMR selain menjadikan matematika bermakna juga melibatkan siswa untuk aktif dalam pembelajaran hal ini akan berdampak baik pada hasil belajar. Seperti yang dikemukakan oleh Djamarah (2007: 43) bahwa: "Belajar sambil melakukan aktivitas lebih banyak mendatangkan hasil bagi anak didik, sebab kesan yang dapat didapatkan oleh anak didik lebih tahan lama tersimpan didalam benak anak didik". Selanjutnya aktivitas pembelajaran yang berbasis budaya Aceh akan membentuk pribadi individu yang mencintai budaya daerahnya, suasana belajar lebih aktif sehingga hasil yang ingin dicapai sesuai dengan yang diharapkan, khususnya meningkatkan hasil belajara dan aktivitas siswa dikelas. 


\section{METODE PENELITIAN}

Penelitian ini dikategorikan sebagai penelitian eksperimen dengan pendekatan kuantitatif. Sesuai dengan desain yang digunakan maka akan diteliti dua kelas sebagai kelas eksperimen dan kontrol, karena tidak ada perbedaan faktor keacakan yang dipilih maka penelitian ini tergolong quasi eksperimen. Pengumpulan data dilakukan dua kali, yaitu pemberian tes awal (pre - test) dan tes akhir ( post test). Data tes tersebut digunakan untuk melihat peningkatan hasil belajar matematika siswa mengunakan rumus gain ternomalisasi. Menurut Hake (dalam Meltzer 2002) secara sederhana gain absolut dengan gain maksimum yang mungkin (ideal), dapat dihitung dengan :

$$
g=\frac{\text { skor postes }- \text { skor pretes }}{\text { skor maksimal ideal }- \text { skor pretes }}
$$

Kriteria interpretasinya adalah :

$$
\begin{aligned}
& g \text { - tinggi jika } g>0,7 \\
& g \text { - sedang jika } 0,3<g \leq 0,7 \\
& g \text { - rendah jika } g \leq 0,3
\end{aligned}
$$

Sedangkan angket diberikan kepada responden dengan tujuan untuk memperoleh informasi atau masukan dari para responden tentang bagaimana aktifitas siswa jika diajarkan dengan pendekatan RME berbasis Budaya Aceh.

\section{Prosedur Penelitian}

Penelitian ini dilakukan diawali dengan studi pendahuluan untuk merumuskan identifikasi masalah, merumuskan masalah dan studi literatur yang pada akhirnya diperoleh perangkat penelitian berupa bahan ajar dan instrumen penelitian. Perangkat penelitian ini sebelum diujicobakan telah dilakukan validasi oleh para pakar pendidikan yang berkompeten. Hasil perhitungan validitas tiap item tes ujicoba soal tes hasil belajar matematika siswa dapat dilihat pada tabel berikut:

\begin{tabular}{|c|c|c|c|c|c|c|c|c|c|}
\hline \multirow{2}{*}{ No } & \multirow{2}{*}{$r_{X Y}$} & \multicolumn{5}{|c|}{ Interpretasi Validitas } & \multirow{2}{*}{$t_{\text {hitung }}$} & \multirow{2}{*}{$t_{\text {tabel }}$} & \multirow{2}{*}{ Keputusan } \\
\hline & & $\mathrm{SR}$ & $\mathrm{RD}$ & $\mathrm{SD}$ & $\mathrm{TG}$ & $\mathrm{ST}$ & & & \\
\hline 1 & -0.085 & $\sqrt{ }$ & & & & & 0.427 & 1.706 & Tidak Valid \\
\hline 2 & 0.633 & & & & $\sqrt{ }$ & & 4.169 & 1.706 & Valid \\
\hline 3 & 0.467 & & & $\sqrt{ }$ & & & 2.457 & 1.706 & Valid \\
\hline 4 & 0.590 & & & $\sqrt{ }$ & & & 3.812 & 1.706 & Valid \\
\hline 5 & 0.661 & & & & $\sqrt{ }$ & & 4.491 & 1.706 & Valid \\
\hline 6 & 0.579 & & & $\sqrt{ }$ & & & 3.621 & 1.706 & Valid \\
\hline 7 & 0.432 & & & $\sqrt{ }$ & & & 2.472 & 1.706 & Valid \\
\hline 8 & 0.604 & & & & $\sqrt{ }$ & & 3.864 & 1.706 & Valid \\
\hline 9 & 0.441 & & & $\sqrt{ }$ & & & 2.541 & 1.706 & Valid \\
\hline 10 & 0.644 & & & & $\sqrt{ }$ & & 4.292 & 1.706 & Valid \\
\hline
\end{tabular}

Berdasarkan hasil uji coba, diperoleh, untuk soal tes hasil belajar matematika siswa, dari 10 soal hanya ada satu soal yang tidak valid, dan hanya 5 butir yang digunakan yaitu butir soal nomor 2,4,5,8 dan 10, soal tersebut dipilih karena memiliki nilai korelasi yang tinggi dan juga mewakili setiap indikator soal.

Selanjutnya pemilihan subyek penelitian sebagai kelas kontrol dan kelas eksperimen, sebelum dilaksanakan tindakan terlebih dahulu dilakukan pretest untuk kedua kelas tersebut. Selama dilakukan tindakan berupa pendekatan pembelajaran yaitu pendekatan RME pada kelas eksperimen dan pendekatan biasa pada kelas kontrol dilakukan analisis terhadap tes hasil belajar siswa. Tes hasil 
tes hasil belajar siswa digunakan untuk analisis data secara kuantitatif sekaligus kualitatif. Analisis kuantitatif untuk melihat perbedaan peningkatan hasil belajar siswa pada pendekatan RME berbasis budaya Aceh dan pendekatan biasa, sedangkan analisis kualitatif untuk melihat bagaimana aktivitas siswa terhadap pembelajaran RME berbasis budaya Aceh. Singkatnya penelitian ini dikelompokkan dalam tiga tahap, yaitu: tahap persiapan, tahap pelaksanaan, dan tahap analisis data.

\section{PEMBAHASAN}

Penelitian ini dilaksanakan di SD Negeri Negeri 2 Lhokseumawe yaitu sebuah SD yang terletak di Pusat Kota Lhokseumawe. Materi yang diteliti yaitu penjumlahan dan pengurangan bilangan sampai 500, perkalian dan pembagian serta pengenalan bangun datar segi -4 yang merupakan materi semester ganjil tahun ajaran 2019/ 2020. Penelitian berlangsung sebanyak 18 kali pertemuan, pertemuan pertama adalah pelaksanaan pre test dilanjutkan dengan pemberian materi sebanyak enam belas kali pertemuan kali pertemuan dan pertemuan ke-18 pelaksanaan post test untuk kelas eksperimen maupun kelas kontrol.

Berdasarkan hasil pengolahan data uji perbedaan rata-rata peningkatan hasil belajar matematika siswa diperoleh bahwa siswa kelas ekperimen yaitu yang memperoleh pembelajaran PMR berbasis budaya Aceh, menunjukkan peningkatan hasil belajar matematika lebih tinggi dibandingkan dengan siswa kelas kontrol yang memperoleh pembelajaran biasa. Terlihat dari nilai N-gain untuk kelas eksperimen dan kelas kontrol dan dari hasil tersebut terbukti bahwa pembelajaran PMR berbasis budaya Aceh dapat meningkatkan hasil belajar matematika siswa jika dibandingkan pembelajaran biasa. Hasil perhitungannya dapat dilihat pada Tabel berikut:

\begin{tabular}{|c|c|c|c|c|}
\hline \multirow{2}{*}{$\begin{array}{c}\text { Peningkatan } \\
\text { Hasil } \\
\text { Belajar }\end{array}$} & \multicolumn{2}{|c|}{ Kel. Eksperimen } & \multicolumn{2}{c|}{ Kel. Kontrol } \\
\cline { 2 - 5 } & $\begin{array}{c}\text { Rata-Rata Gain } \\
\text { Ternormalisasi }\end{array}$ & Kategori & $\begin{array}{c}\text { Rata-Rata Gain } \\
\text { Ternormalisasi }\end{array}$ & Kategori \\
\cline { 2 - 5 } & 0.53 & Sedang & 0.29 & Rendah \\
\hline
\end{tabular}

Secara diagram dapat dilihat rata-rata dan simpangan baku dari 2 kelompok sebagai berikut:

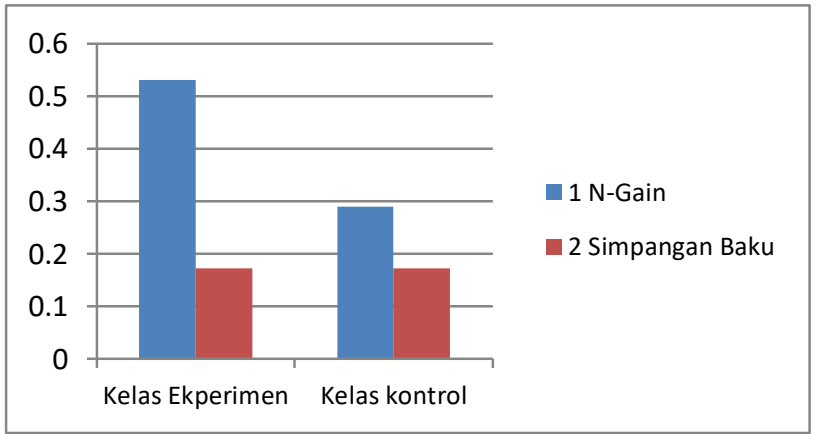

Marpaung (2004:) dalam penelitiannya di kelas IV dan kelas V di Sekolah Dasar yang berkualitas sedang menunjukkan bahwa kelompok PMR lebih baik dari pada kelompok Non-PMR, penelitian ini didukung juga dengan uji perbedaan rata-rata antara kelompok PMR dan kelompok Non-PMR yang berbeda secara signifikan. Hampir sama dengan temuan di atas, Widjaja (2010) yaitu dengan pembelajaran matematika realistik pembelajaran dikelas akan meningkatkan keaktifan siswa dalam proses pembelajaran dengan demikian, dengan PMR guru dapat mengatur proses pembelajaran melalui proses berpikir siswa dari masalah nyata sebagai model of sampai ke bentuk model matematika formal (model for). 
Adapun gambaran pembelajaran matematika realistik yang dilaksanakan dalam penelitian ini dapat dilihat pada ice birgRME( gunung es PMR ) sebagai berikut:

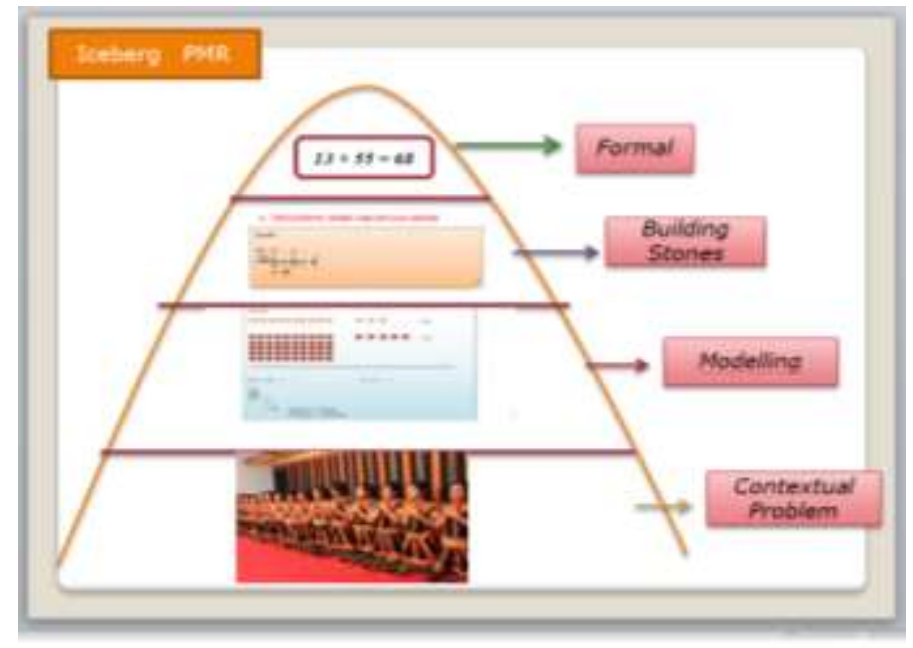

Ice birg PMR

Berdasarkan ice birg PMR di atas terlihat bahwa pembelajaran matematika realistik berbasis budaya Aceh diawali mengajukan masalah realistik, berupa suatu masalah dimana seseorang ingin menghitung jumlah pemain saman jika ditambahkan dari jumlah semula. Disini siswa akan memikir bersama - sama dalam kelompok bagaimana dan apa yang harus dilakukan untuk mencari solusi dari hal yang diajukan guru agar jumlah keseluruhan pemain saman dapat dihitung.

Memanfaatkan masalah-masalah nyata pada lingkungan budaya Aceh menjadikan sumber belajar yang membuat siswa belajar lebih bermakna, dan menghargai matematika sebagai disiplin ilmu yang bermanfaat bagi kehidupan sehari-hari. Contoh masalah nyata pada setiap lembar aktivitas ( LAS), membuat siswa menyadari bahwa banyak sekali budaya - budaya Aceh yang belum mereka tahu dan ternyata matematika sering dijumpai dalam kehidupannya. Antusiasme siswa terlihat siswa berlomba - lomba saling bertanya tentang masalah yang diberikan karena banyak siswa - siswa tidak paham dengan istilah dalam bahasa Aceh dan nama budaya yang terdapat pada permasalahan yang diberikan. Hal tersebut merupakan apresiasi yang luar biasa bagi siswa ketika matematika itu diajarkan secara bermakna dalam kehidupan.

Berdasarkan keseluruhan dan kesimpulan dari observasi aktivitas siswa menunjukkan bahwa respon siswa positif terhadap PMR berbasis budaya Aceh, dengan mendapatkan persentase tertinggi yaitu 95.3 dibanding poin - poin yang lain. Dari 16 kali pertemuan terlihat persentase aktivitas siswa cenderung meningkat. Pada kelas eksperimen yang diajarkan dengan PMR berbasis budaya Aceh juga terlihat siswa lebih aktif dan lebih antusias menerima pelajaran matematika.

Hal ini menunjukkan bahwa pembelajaran PMR berbasis budaya Aceh menjadikan matematika menarik untuk dipelajari disamping memperoleh ilmu matematika siswa juga memperoleh pengetahuan baru yang berkaitan dengan yang dipelajari dalam matematika yang merupakan karakteristik dari PMR itu sendiri yaitu intertwinment (keterkaitan). Temuan ini mendukung teori yang dikemukakan oleh Suydam dan Weaver dalam Turmudi (2008), bahwa: Guru dan pendidik matematika lainnya, umumnya mempercayai bahwa siswa belajar lebih efektif manakala mereka tertarik dengan apa yang mereka pelajari dan mereka berprestasi baik kalau mereka menyukai matematika .

\section{KESIMPULAN}

Berdasarkan hasil penelitian dan pembahasan maka diperoleh kesimpulan sebagai berikut: 
1. Peningkatan Hasil Belajar matematika siswa dengan pembelajaran PMR berbasis budaya Aceh lebih baik daripada peningkatan hasil belajar yang mendapat pembelajaran biasa / konvensional.

2. Aktivitas siswa dalam pembelajaran PMR berbasis budaya Aceh menunjukkan lebih aktif dan meningkat, persetase aktivitas siswa menunjukkan siswa merasa senang dan tertarik dengan masalah realistik budaya Aceh yang diberikan guru.

\section{REFERENCES}

Afgani, J. (2011) . Analisis Kurikulum Matematika. Jakarta : Universitas Terbuka

Akdon. (2008). Aplikasi Statistika Dan Metode Penelitian Untuk Administrasi Dan Manajemen. Bandung: Dewa Ruchi.

Arikunto, Suharsimi. 2006. Prosedur Penelitian Suatu Praktik. Jakarta: PT Rineka Cipta

Azmi, N (2018).Realistic Mathematics Education based on Acehnese Culture: One Way to Improve Problem Solving Ability of Elementary School Students. Prociding pada South East Asia Design research International Conference. 27 - 28 june ,Banda Aceh

Djamarah dan Zain. 2007. Strategi Belajar Mengajar. Jakarta : PT. Rineka

De Lange, Jzn . (1996) Mathematics, Insight and Meaning. Nederlands.

Erman, S. H. (2003) Evaluasi Pembelajaran Matematika.Bandung : UPI

Gravemeijer ,K.1994. Developing Realistik Mathematics Education.(Utrecht : Freudenthal Institute

Johar, Rahmah dan Afrina. M (2011). The Teachers' Efforts to Encourage the Students' Strategies to Find the Solution of Fraction Problem in Banda Aceh. Makalah disajikan pada International Conference of school Effectiveness and Improvement (ICSEI) at Limassol, Cyprus , 4 s.d 7 januari 2011

Komalasari, K. (2011). Pembelajaran Kontekstual Konsep dan Aplikasi. Bandung : Refika Aditama

Mulyono. (2004). Melalui PMRI Penghargaan Kepada Siswa Terbentuk. Buletin PMRI. Edisi Kelima - Oktober hal.3.

Marpaung, Y. 2004. Reformasi Pendidikan Matematika di Sekolah Dasar.

Sembiring, R. Dkk A .2010. Decade of PMRI in Indonesia.Bandung : Utrecht

Sinta Armalita dan Yuriani. 2016. Faktor-faktor yang Mempengaruhi Minat untuk Melanjutkan Studi ke Perguruan Tinggi Siswa Kelas XII Jurusan Tata Boga di SMK Negeri 4 dan SMK Negeri 6 Yogyakarta. Yogyakarta: Jurnal Pendidikan Teknik Boga,Universitas Negeri Yogyakarta

Sudjana, 2005 Metode Statistika. Bandung: Tarsito

Susanto.A. 2012. Perkembangan Anak Usia Dini Pengantar Dalam Berbagai Aspeknya”. Jakarta:Kencana Prenada Media Group

Sri Anitah dan Janet Trineke, Strategi Pembelajaran Matematika, (Jakarta: UT . 2007),h.7

Streefland .L .Realistic Mathematics Education in Primary School . Freudenthal institute : The Netherland

Suryadi, D. 2012. Membangung Budaya Baru dalam Berpikir Matematika. Bandung: Rizkqi Press 
Suyadi. 2010. Psikologi Belajar PAUD (Pendidikan Anak Usia Dini). Yogyakarta: Pedagogia.

Widjaja, W. (2010) The Role of Contexts and Teacher's Questioning to Enhane Students' thinking. Journal of Science and Mathematics Education in Southeast Asia 2010, Vol.33 No. 